\title{
Germanica
}

GERMANICA

$53 \mid 2013$

Littérature et cinéma dans l'espace germanophone contemporain : jeux intermédiaux, modes de transfert, adaptations

\section{Der Mann ohne Eigenschaften}

\section{Alexander Kluge}

\section{(2) OpenEdition}

\section{Journals}

Édition électronique

URL : http://journals.openedition.org/germanica/2295

DOI : 10.4000/germanica.2295

ISSN : 2107-0784

Éditeur

Université de Lille

Édition imprimée

Date de publication : 30 décembre 2013

Pagination : 249-250

ISBN : 9782913857322

ISSN : 0984-2632

\section{Référence électronique}

Alexander Kluge, « Der Mann ohne Eigenschaften », Germanica [Online], 53 | 2013, Online erschienen am: 30 Dezember 2016, abgerufen am 06 Oktober 2020. URL : http://journals.openedition.org/ germanica/2295; DOI : https://doi.org/10.4000/germanica.2295

(c) Tous droits réservés 


\title{
Der Mann ohne Eigenschaften
}

\author{
Alexander KLUGE
}

Einer der deutschen Autorenfilmer hatte eine Kalkulation aufgestellt, aber noch nicht bei den Gremien einreichen können. Es sollte sein nächster Versuch werden. Er neigte zur Verfilmung von Robert Musils Der Mann ohne Eigenschaften, von dem es heißt, es sei DeR Roman Des JAHRHUNDERTS.

Der Produzent fragte den Regisseur :

- Wollen Sie selber inszenieren?

- Ja.

- Wenn Sie das Thema mal umreißen, ich kenne den Roman nicht, bzw. ich habe ihn nicht zu Ende gelesen.

- Bis wohin haben Sie denn gelesen?

- Den Anfang.

- Das tun die meisten.

- Wenn Sie den Inhalt mal in ein paar Sätzen andeuten?

- Der Mann ohne Eigenschaften...

- Ist klar. Der hat keine Eigenschaften. Aber wieso nicht ?

- Das ist der Titel.

- Handelt das Buch denn nicht davon?

- Es handelt von einem Geschwisterpaar.

- Mit oder ohne Inzest?

- Weiß man nicht genau. Einige Stellen gegen Ende des Buches deuten eher auf Inzest, andere sprechen dagegen. Der Mann heißt Ulrich, seine Schwester Agathe.

- Aha. Und der Inhalt?

- Sie meinen die Handlung ?

- Was passiert ?

- Der Mann hat keine Eigenschaften. Das sagt etwas aus über das zwanzigste Jahrhundert. Das Buch enthält eine scharfsinnige Analyse des zwanzigsten Jahrhunderts. 
- Und was kommt heraus?

- Das steht nicht im Buch.

- Vielleicht muß man es im Film hinzufügen?

- Ich wollte eigentlich bei dem Buch bleiben.

- Ja, Sie müßten aber dem Zuschauer die Handlung mitteilen. Sie können nicht sagen, dieser Ulrich hatte keine Eigenschaften, und eine Handlung gibt's auch nicht, und was das Jahrhundert angeht, wissen wir nicht, was herauskommt, und der Film hat keinen Anfang, kein Ende, und einen Mittelteil schon gar nicht. Das wäre z.B. für eine Vorankündigung ungeeignet.

- Man kann jeden Stoff zerreden, wenn man so redet wie Sie.

- Der Mann ohne Eigenschaften ist an sich ein ganz guter Titel. Man denkt sich was dabei.

- Sie sind also mit dem Stoff einverstanden?

- Sagen wir mal so: Ihr Hinweis, daß man jeden Stoff zerreden kann, wenn man die Ausdrücke richtig wählt, hat mich beeindruckt. Lauter Kurzfassungen, und danach veröffentlichen wir, daß das berühmte Stoffe sind. Dann muss der Zuschauer aufpassen.

- Nur Inhaltsangaben?

- Ja. Und davon viele. Sozusagen der Film Ohne Eigenschaften. Junge Frau, die sich zu nichts entschließen kann, bekommt auch nicht den Mann, von dem sie glaubt, daß sie ihn will. Den anderen will sie aber auch nicht, darüber vergehen die Jahre. Ihr Kind verunglückt, und man weiß nicht, ob sie ihren Mann noch einmal wiedersieht. Der, von dem sie nur glaubte, daß sie ihn liebt, ist inzwischen gestorben. "Vom Winde verweht"! Herrlicher Stoff !

- Könnte man gleich mit einfügen.

- Sagen Sie, das ergibt ein wunderbares Ratespiel!

- Ich hatte aber vor, den Film über DeR MANN OHNE EIGENSCHAFTEN...

- Ich bin von meiner Lösung ganz begeistert. Man muß die Eigenschaften weglassen. Der Mann, das wäre ein ganz brauchbarer Titel, hätte auch was mit dem zwanzigsten Jahrhundert zu tun.

- Ich hatte mich aber entschieden...

- Ja, ich weiß, aber ich halte Ihre Lösung nicht für schlagkräftig. Sie müssen mich ja nicht fragen, wenn Sie meinem Rat nicht folgen wollen.

- Was für einem Rat?

- Na ja, Sie hören nicht zu. 